Д-р техн. наук В.І. Мороз, канд. техн. наук О.В. Братченко, стари. викл. С.В. Бобрицький, B.I. Громов

\title{
УДОСКОНАЛЕННЯ ТЕХНОЛОГІЇ ПРОЕКТУВАННЯ ТЯГОВИХ ЗУБЧАТИХ ПЕРЕДАЧ МОТОРВАГОННОГО РУХОМОГО СКЛАДУ
}

Постановка проблеми i аналіз останніх результатів досліджень. Одним 3 найважливіших показників, що відображають розвиток індустріальної європейської держави, є обсяг внутрішніх вантажних та пасажирських перевезень. В Україні на залізничний транспорт припадає 49 \% вантажообігу та більше ніж 
43\% пасажирообігу. За оцінками спеціалістів, більша частина (близько 70\%) обсягу пасажирських перевезень припадає на приміське сполучення, що пояснюється концентрацією значних приміських пасажиропотоків навколо великих промислових центрів.

Приміські перевезення на залізницях виконуються моторвагонним рухомим складом (МВРС), який об'єднує електропоїзди (63\% парку), дизель-поїзди $(36 \%)$ та рейкові автобуси (1\%). Тому Державними цільовими програмами розвитку залізничного транспорту України $[1,2]$ як пріоритетний напрямок у забезпеченні високої якості приміських перевезень визначено подальший розвиток електричного приміського транспорту.

На цей час парк МВРС України в основному представлений електропоїздами (ЕП) постійного струму (серії ЕР-1, ЕР-2, ЕР-2т, ЕР-2p, ЕТ-2, ЕД-2т, ЕПЛ-2т) та змінного струму (серії ЕР-9п, ЕР-9М, ЕР-9т, ЕР-9е, ЕПЛ-9т, ЕД-9м), більша частина 3 яких працює у наднормативний термін [3]. 3 урахуванням повільного впровадження нових серій ЕП актуальності набувають науково-дослідні та дослідноконструкторські роботи, спрямовані на обгрунтоване подовження встановлених заводами-виробниками строків експлуатації МВРС. Серед комплексу таких робіт слід виділити розробки, спрямовані на забезпечення експлуатаційної надійності та довговічності основних конструктивних модулів секцій ЕП, до яких належать екіпажна частина, тяговий привод i, зокрема, тягова зубчата передача (ТЗП).

Характер виявлених у результаті досліджень [4] пошкоджень (втомні тріщини вінця в районі ніжок зубців, інтенсивний знос активних профілів зубців та інші) свідчить про недосконалість конструкції ТЗП. Це потребує удосконалення технології їх проектування.

Одним 3 ключових моментів технології проектування ТЗП $є$ вибір розрахункових коефіцієнтів зміщення $x_{1}$ i $x_{2}$ при виготовленні шестерень та зубчатих коліс за умови отримання високих якісних показників при забезпеченні незмінної міжосьової відстані.

Найбільш розповсюдженими при проектуванні зубчатих передач до вибору коефіцієнтів $x_{1}$ і $x_{2}$ є підходи за окремими критеріями $[5,6]$ :

1. При проектуванні ЗП за критерієм максимальної контактної міцності використовуються таблиці, складені проф. Кудрявцевим В.М. Для відповідних чисел зубців $z_{1}$ i $z_{2}$ з таблиць вибираються коефіцієнти зміщення $x_{1}$ i $x_{2}$, сума яких $\left(x_{\Sigma}=x_{1}+x_{2}\right)$ максимально можлива за умов відсутності підрізання та загострення зубців, а також забезпечення вимоги $\varepsilon_{\alpha} \geq 1,1$.

2. При проектуванні ЗП за критерієм мінімального спрацювання активних профілів зубців використовуються таблиці, складені у Центральному конструкторському бюро редукторобудування (ЦКБР). Для відповідних чисел зубців $z_{1}$ і $z_{2}$ $\left(z_{1}+z_{2} \geq 34\right) \quad 3$ таблиць вибираються коефіцієнти зміщення $x_{1}$ i $x_{2}\left(x_{1}=-x_{2}\right)$ за умов забезпечення $\left|\lambda_{1 \max }\right|=\left|\lambda_{2 \max }\right|$, відсутності підрізання та загострення зубців, а також забезпечення вимоги $\varepsilon \geq 1,1$.

Більш обгрунтованим $є$ вибір коефіцієнтів $x_{1}$ і $x_{2}$ на основі використання альбому “блокувальних контурів” (додатки до стандарту ГОСТ 16532-70).

В той же час наведені способи не враховують особливостей конструкції ТЗП, що суттєво ускладнює процес їх проектування. Це визначає актуальність проведення досліджень, спрямованих на удосконалення технології проектування ТЗП МВРС на основі обгрунтованого вибору коефіцієнтів зміщення.

$\begin{array}{ccr}\text { Метою } & \text { статті } \epsilon & \text { висвітлення } \\ \text { розробленого } & \text { авторами } & \text { варіанта }\end{array}$


удосконалення технології проектування ТЗП за рахунок раціонального вибору розрахункових коефіцієнтів зміщення $x_{1}$ i $x_{2}$ для шестерень та коліс, які входять до складу тягових зубчатих передач МВРС.

\section{Удосконалення}

технології проектування тягових зубчатих передач моторвагонного рухомого складу. На відміну від розглянутих вище підходів, пропонується визначати коефіцієнти $x_{1}$ i $x_{2}$ на основі комплексного розгляду основних умов на проектування, головна 3 яких описується відповідними узагальненими математичними моделями, де змінними є коефіцієнти $x_{1}$ i $x_{2}$. При цьому основними умовами на проектування $€$ : числа зубців шестірні $z_{1}$ і колеса $z_{2}$; відсутність загострення, підрізання та інтерференції зубців шестірні і колеса; забезпечення потрібної міжосьової відстані $a_{w}$; безперервність та плавність зачеплення в ТЗП ( $\varepsilon \geq \varepsilon_{\min }$ ); вирівнювання коефіцієнтів питомих ковзань профілів зубців; рівні контактних напружень (відповідають коефіцієнтам питомих тисків $v_{p}$ ).

За своєю суттю потрібні розрахункові коефіцієнти $x_{1}^{*}$ i $x_{2}^{*}$ визначаються на основі вирішення задачі багатовимірної оптимізації 3 обмеженнями. 3 метою забезпечення найменш інтенсивного зношування робочих профілів зубців при проектуванні слід забезпечити найменшу різницю між максимальними значеннями коефіцієнтів питомих ковзань шестірні $\left|\lambda_{1 \max }\right|$ та колеса $\left|\lambda_{2 \max }\right|$, тобто мінімальні значення показника $\Delta \lambda=\left|\lambda_{\max }-\lambda_{2 \max }\right|$, який обрано як основний критерій. Обрані інтервали варіювання $x_{1 \text { min }} \ldots x_{1 \max }$ i $x_{2 \min } . x_{2 \max }$ враховуються у вигляді параметричних обмежень, вимоги $a_{w}=a_{w \kappa}, \quad \varepsilon_{\alpha} \geq \varepsilon_{\alpha \min }, \quad s_{a l, 2} \geq 0,25 \cdot m$ враховуються у вигляді функціональних обмежень (реалізація процедури згортання векторного критерію).

Математичний запис задачі, що розглядається, має вигляд

$$
\begin{aligned}
& \Delta \lambda\left(x_{1}^{*}, x_{2}^{*}\right) \rightarrow \min , \\
& x_{1}^{*}, x_{2}^{*} \in Д_{x} \in Д,
\end{aligned}
$$

де $x_{1}^{*}, x_{2}^{*}-$ оптимальні значення коефіцієнтів $x_{1}$ і $x_{2}$, які вибираються в зоні допустимих рішень Д можливих рішень Д.

При цьому область можливих рішень, що визначається інтервалами варіювання змінних параметрів $x_{1}$ i $x_{2}$,

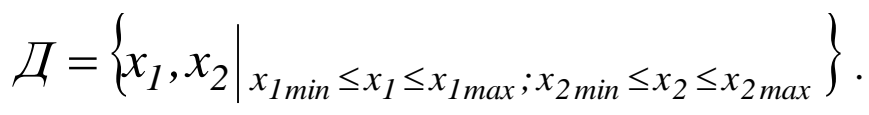

Область допустимих рішень при проектуванні ТЗП з урахуванням функціональних обмежень

$$
Д_{x}=\left\{\begin{array}{l|l}
x_{1}, x_{2} & \begin{array}{l}
a_{w}=a_{w \kappa} ; \varepsilon_{\alpha} \geq 1,4 ; s_{a 1,2} \geq 0,25 m ; \\
x_{1 \min } \leq x_{1} \leq x_{1 \max } ; x_{2 \min } \leq x_{2} \leq x_{2 \max }
\end{array}
\end{array}\right\} .
$$

При виборі коефіцієнтів $x_{1}^{*}$ і $x_{2}^{*}$ доцільно використовувати допоміжні номограми (див. рисунок), що будуються 3 використанням отриманих на основі методів математичного планування 
експериментів відповідних узагальнених математичних моделей (УММ) і описують зміну критеріального показника та функціональних обмежень залежно від змінних $x_{1}^{*}$ i $x_{2}^{*}$.
Наприклад, для електропоїзда серії ЕР-2 вибір розрахункових коефіцієнтів зміщення $x_{1}^{*}, x_{2}^{*}$ здійснювався на основі комплексної номограми, аналогічної до показаної на рисунку, 3 використанням наведених нижче УММ:

$$
\begin{aligned}
& \varepsilon=1,7-0,314 \cdot x_{1}-0,154 \cdot x_{2}-0,03 \cdot x_{1}^{2}-0,022 \cdot x_{2}^{2}+0,055 \cdot x_{1} \cdot x_{2} \\
& \Delta \lambda=-1,9+4,71 \cdot x_{1}-0,057 \cdot x_{2}-1,56 \cdot x_{1}^{2}+0,024 \cdot x_{2}^{2}-0,46 \cdot x_{1} \cdot x_{2} \\
& a_{w}=479,8+10,13 \cdot x_{1}+10,13 \cdot x_{2}-0,54 \cdot x_{1}^{2}-0,54 \cdot x_{2}^{2}-1,04 \cdot x_{1} \cdot x_{2} \\
& v_{p}=0,34-0,067 \cdot x_{1}-0,067 \cdot x_{2}+0,01 \cdot x_{1}^{2}+0,01 \cdot x_{2}^{2}+0,022 \cdot x_{1} \cdot x_{2} \\
& s_{a 1}=7,14-3,173 \cdot x_{1}+0,0135 \cdot x_{2}-0,58 \cdot x_{1}^{2}+0,586 \cdot x_{2}^{2}+1,52 \cdot x_{1} \cdot x_{2} \\
& \operatorname{Int}_{1}=10,89+26,88 \cdot x_{1}+5,04 \cdot x_{2}-1,64 \cdot x_{1}^{2}-0,52 \cdot x_{2}^{2}-3,41 \cdot x_{1} \cdot x_{2}
\end{aligned}
$$

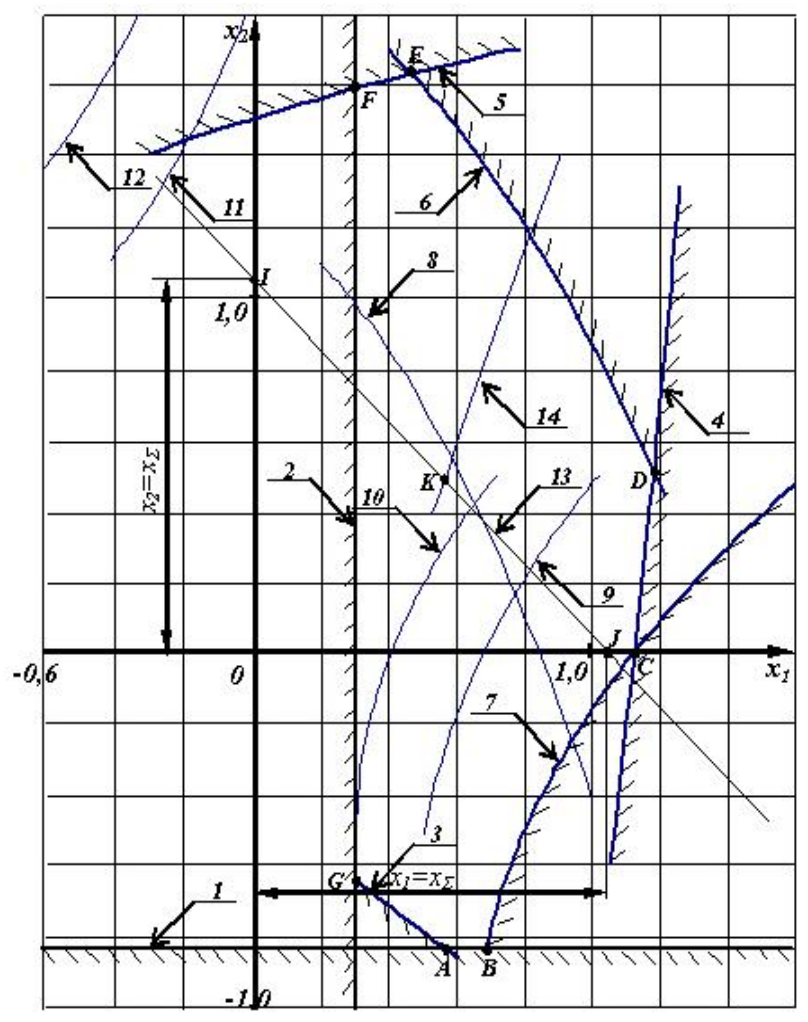

Рис. Комплексна номограма для вибору коефіцієнтів $x_{1}$ і $x_{2}$ при проектуванні ТЗП
Видно, що область $Д_{x}(A-B-C-D-E-F-G-A)$ обмежена відповідними лініями:

1 - лінія $x_{1 \text { min }}=1-0,0585 \cdot z_{1}$;

2 - лінія $x_{2 \min }=1-0,0585 \cdot z_{2}$;

3, 4, 5 - граничні лінії відсутності інтерференції зубців;

6 - лінія $\varepsilon=1,0$;

7 - лінія недопустимості загострення зубців $s_{a 1} / m=0$.

Окрім цього, для забезпечення відповідних вимог на проектування ТЗП у координатах $x_{1}$ i $x_{2}$ побудовано такі допоміжні лінії:

$8-\varepsilon=1,2$;

$9-s_{a 1} / m=0,25$;

$10-s_{a l} / m=0,4$;

$11-s_{a 2} / m=0,25$;

$12-s_{a 2} / m=0,4$;

13 - лінія заданого відносного значення міжосьової відстані $a_{w}$;

$14-\Delta \lambda=0$. 
Аналіз отриманих результатів показав, що в ТЗП із запропонованими коефіцієнтами зміщення $\left(x_{1}^{*}=0,385, x_{2}^{*}=0,135\right)$ у порівнянні із серійною, збільшується коефіцієнт перекриття $\varepsilon$ на 7-10\%, зменшуються напруження згину зубців шестірні і колеса на $10 \%$, вирівнюються максимальні питомі ковзання на ніжках зубців $\Delta \lambda=\lambda_{1 \max }-\lambda_{2 \max }=0$, що дозволить знизити інтенсивність зносу зубців до $40 \%$.
Висновки i рекомендації щодо подальшого використання. Наведені у статті матеріали підтвердили, що запропонована авторами методика дозволяє здійснювати обгрунтований вибір коефіцієнтів зміщення $x_{1}$ i $x_{2}$ зуборізного інструменту 3 метою покращення якісних показників зачеплення. Це обгрунтовує доцільність іiі використання в дослідженнях, які спрямовані на створення ТЗП нового та модернізацію існуючого MBPC.

\section{Сиисок літератури}

1. Державна цільова програма реформування залізничного транспорту: постанова Кабінету Міністрів України від 16.12.2009 р. № 1390. - К., 2009. - Режим доступу: http://zakon4.rada.gov.ua/laws/show/1390-2009-\%D0\%BF.

2. Стратегія розвитку залізничного транспорту на період до 2020 року: розпорядження Кабінету Міністрів України від 16.12.2009 р. №1555-р. - К., 2009. - Режим доступу: http://zakon4.rada.gov.ua/laws/show/1555-2009-\%D1\%80.

3. Тартаковський, Е.Д. Пріоритетні напрямки досліджень у галузі тягового рухомого складу [Текст] / Е.Д. Тартаковський // Зб. наук. праць. - Харків: УкрДАЗТ, 2004. - Вип. 64. C. 5-12.

4. Мороз, В.І. Обгрунтування перспективних напрямків підвищення експлуатаційної надійності тягових передач електропоїздів серії ЕР-2 [Текст] / В.I. Мороз, О.В. Братченко, С.В. Бобрицький // Зб. наук. праць. - Харків: УкрДАЗТ, 2009. - Вип. 111. - С. 176-182.

5. Кіницький, Я.Т. Теорія механізмів і машин [Текст]: підручник / Я.Т. Кіницький. - К.: Наукова думка, 2002. - 660 с.

6. Кореняко, О.С. Теорія механізмів і машин [Текст] / О.С. Кореняко. - К.: Вища школа, 1987. - 206 с.

7. Мороз, В.І. Основи конструювання і САПР [Текст]: навч. посібник / В.I. Мороз, О.В. Братченко, В.В. Ліньков. - Харків: Нове слово, 2003. - 194 с.

8. Мороз, В.I. Основи конструювання і САПР технічних засобів залізничного транспорту [Текст] / В.І. Мороз, О.В. Братченко, К.В. Астахова. - Харків: УкрДАЗТ, 2009. $136 \mathrm{c}$.

Ключові слова: моторвагонний рухомий склад, електропоїзд ЕР-2, тяговий привод, тягова зубчата передача, зубчаті колеса, технологія проектування, технологія ремонту, математичні залежності.

\section{Анотації}

В статті обгрунтовано необхідність удосконалення технології проектування тягових зубчатих передач моторвагонного рухомого складу за рахунок вибору розрахункових коефіцієнтів зміщення $x_{1}$ i $x_{2}$ при виготовленні шестерень та зубчатих коліс за умови 
отримання високих якісних показників. Розглянуто найбільш розповсюджені підходи до їх вибору. Запропонована процедура вибору $x_{1}$ i $x_{2}$ на основі вирішення задачі багатовимірної оптимізації з обмеженнями. Наведені математичні моделі для вибору коефіцієнтів зміщення на прикладі ТЗП електропоїзда серії ЕР-2. Подані рекомендації щодо подальшого застосування запропонованої методики в дослідженнях, які спрямовані на створення ТЗП нового та модернізацію існуючого МВРС.

В статье обоснована необходимость усовершенствования технологии проектирования тяговых зубчатых передач моторвагонного подвижного состава за счет выбора расчетных коэффициентов смещения $x_{1}$ и $x_{2}$ при изготовлении шестерен и зубчатых колес при условии получения высоких качественных показателей. Рассмотрены наиболее распространенные подходы к их выбору. Предложена процедура выбора $x_{1}$ и $x_{2}$ на основе решения задачи многомерной оптимизации с ограничениями. Приведены математические модели для выбора коэффициентов смещения для ТЗП электропоезда серии ЭР-2. Представлены рекомендации по дальнейшему применению предложенной методики в исследованиях, которые направлены на создание ТЗП нового и модернизацию существующего МВПС.

In the articles the necessity of improvement of technology of planning of the hauling gearings of multiple unit rolling stock is grounded due to the choice of calculation coefficients of displacement $x_{1}$ and $x_{2}$ at making of cog-wheels and gear-wheels on condition of receipt of high high-quality indexes. The most widespread approaches are considered on their choice. Procedure of choice is offered $x_{1}$ and $x_{2}$ on the basis of decision of task of multidimensional optimization with limitations. Mathematical models are resulted for the choice of coefficients of displacement for the hauling gearings of electric train of series of ER-2. Presented recommendation on further application of the offered method in researches which are directed on creation of the hauling gearings new and modernization of existent multiple unit rolling stock. 